\title{
Rye, lignans and human health
}

\author{
Göran Hallmans ${ }^{1}$, Jie-Xian Zhang ${ }^{1 *}$, Eva Lundin ${ }^{2}$, Pär Stattin ${ }^{3}{ }_{\mathfrak{\jmath}}$ Anders Johansson ${ }^{1}$, Ingegerd Johansson ${ }^{1}$, \\ Kerstin Hultén ${ }^{1}$, Anna Winkvist ${ }^{1}$, Per Lenner ${ }^{4}$, Per Áman ${ }^{5}$ and Herman Adlercreutz ${ }^{6}$ \\ Departments of Public Health and Clinical Medicine ${ }^{1}$, Pathology ${ }^{2}$, Urology $^{3}$ and Oncology, \\ University of Umeå, SE-901 87 Umeå, Sweden \\ ${ }^{5}$ Department of Food Sciences, Swedish University of Agricultural Sciences, SE-750 07 Uppsala, Sweden \\ ${ }^{6}$ Institute for Preventive Medicine, Nutrition and Cancer, Folkhälsan Research Centre, \\ and Department of Clinical Chemistry, University of Helsinki, Finland
}

\begin{abstract}
Rye bran contains a high content not only of dietary fibre, but also of plant lignans and other bioactive compounds in the so-called dietary fibre complex. Blood concentrations of lignans such as enterolactone have been used as biomarkers of intake of lignan-rich plant food. At present, evidence from studies in human subjects does not warrant the conclusion that rye, whole grains or phyto-oestrogens protect against cancer. Some studies, however, have pointed in that direction, especially in relation to cancers of the upper digestive tract. A number of prospective epidemiological studies have clearly shown a protective effect of wholegrain cereals against myocardial infarctions. A corresponding protective effect against diabetes and ischaemic stroke (brain infarct) has also been demonstrated. It seems reasonable to assume that these protective effects are associated with one or more factors in the dietary fibre complex.
\end{abstract}

\section{Rye: Lignans: Dietary fibre: Cancer: Cardiovascular disease: Diabetes mellitus}

\section{Lignans and rye}

Lignans and isoflavones are two groups of diphenolic substances that are structurally similar to oestradiol, an oestrogen, and are included in the family of phytooestrogens. The isoflavones are more oestrogenic than lignans but are still about 1000 times less active than oestradiol. Plant lignans probably have no or very low oestrogenic activity. Lignans are present in the normal diet, e.g. in vegetables and fruits. Among the grains, rye has a high content of plant lignans. In the mammalian gut plant lignans such as secoisolariciresinol and matairesinol are converted to mammalian lignans, enterolactone (Enl) and enterodiol (End) by the microflora. After this conversion, End is oxidized to Enl. Enl and End are primarily formed in the large intestine, and it is assumed that they are absorbed by passive diffusion in a manner similar to that of shortchain fatty acids.

The biotransformation of plant lignans to mammalian lignans has been studied in both human and animal experiments and in the laboratory. Investigations in patients with ileostomies have shown that, for a complete bioconversion of rye lignans secoisolariciresinol and matairesinol to mammalian lignans Enl and End, the entire enzymic and fermentative activity of the intestine is needed. Thus, subjects with ileostomies are not able to complete the bioconversion (Petterson et al. 1996). In healthy human subjects markedly higher plasma and urinary Enl levels were observed for subjects consuming a diet containing wholegrain rye bread compared with white wheat bread (Juntunen et al. 2000). After a course of antibiotics, it may take more than 1 year before the microflora is again producing Enl normally. The biotransformation of plant lignans to mammalian lignans also depends on the substrates in the gut. In an experiment in which rye bran was fed to mice it was observed that fat decreased the urinary excretion of Enl (Bylund et al. 2000), indicating that fat interfered with the formation of Enl in the gut. Rowland et al. (2000) reported similar results in a human experimental study of soyabean isoflavones. In this case there was a negative correlation between fat in the diet and the urinary equol. Although blood lignans may be affected by many factors (Table 1), the intake of lignan-rich food and the function of the intestinal microflora are still the most important of these factors. Serum Enl has been used as a crude biomarker of lignan intake (Stumpf et al. 2000). 
Rye is a cereal grown almost exclusively in the northwestern part of the Eastern Hemisphere. Approximately $95 \%$ of the global production occurs in the area between the Ural Mountains and the Nordic Sea. Among grains, rye has the highest content of lignans, while soyabean and other legumes are rich in isoflavones (Mazur et al. 1996; Mazur, 1998). Flaxseed has been found to be by far the richest source of lignans. The lignans secoisolariciresinol and matairesinol have been shown to be concentrated in the outer layers of the rye kernel (Nilsson et al. 1997a,b). Recently, high concentrations of some new lignans have been identified in rye, e.g. pinoresinol, lariciresinol, isolariciresinol and syringaresinol. To date, published quantitative results are available only for secoisolariciresinol and matairesinol. Wheat and barley are devoid of matairesinol. All the new lignans, except isolariciresinol, are converted to Enl and End (Heinonen et al. 2001). Rye grain also contains other phenols, e.g. tannins and cinnamic acids, as well as vitamins and minerals (Adlercreutz \& Mazur, 1997).

\section{Cancer}

The incidences of breast and prostate cancer, the major forms of cancer in women and men respectively, vary considerably

Table 1. Some factors which influence the biotransformation of plant lignans to mammalian lignans and the concentration of enterolactone in blood

\begin{tabular}{|c|c|}
\hline & Reference \\
\hline Amount and type of plant lignan in the diet & $\begin{array}{l}\text { Mazur \& Adlercreutz } \\
\text { (1998) } \\
\text { Heinonen et al. (2001) }\end{array}$ \\
\hline $\begin{array}{l}\text { Other dietary factors, e.g. fat content or } \\
\text { increased fat content, will give decreased } \\
\text { biotransformation of lignan in the gut }\end{array}$ & $\begin{array}{l}\text { Bylund et al. (2000) } \\
\text { Rowland et al. (2000) }\end{array}$ \\
\hline $\begin{array}{l}\text { Amount, type and activity of intestinal } \\
\text { bacteria }\end{array}$ & $\begin{array}{l}\text { Adlercreutz \& Mazur } \\
\text { (1997) }\end{array}$ \\
\hline $\begin{array}{l}\text { Other intestinal factors such as the function } \\
\text { of the small and/or large intestine }\end{array}$ & Hallmans et al. (1999) \\
\hline $\begin{array}{l}\text { Constipation is associated with increased } \\
\text { enterolactone concentration }\end{array}$ & Kilkkinen et al. (2001) \\
\hline $\begin{array}{l}\text { High BMI is associated with decreased } \\
\text { enterolactone concentration }\end{array}$ & $\begin{array}{l}\text { Kilkkinen et al. (2001) } \\
\text { Hultén et al. (2002) }\end{array}$ \\
\hline $\begin{array}{l}\text { Smoking is associated with decreased } \\
\text { enterolactone concentration }\end{array}$ & $\begin{array}{l}\text { Kilkkinen et al. (2001) } \\
\text { Hultén et al. (2002) }\end{array}$ \\
\hline
\end{tabular}

between countries, and migration studies have clearly shown that the Western lifestyle has an adverse effect on the incidence of these cancers. It is also evident for prostate cancer that the variation in incidence reflects primarily clinical cancer, while the differences in the incidence of latent cancer are much less pronounced. There is reason to suspect that, to some extent, breast cancer may behave in a similar way, although that behaviour is more difficult to study because of the complex interactions with pregnancies, onset of menarche and other factors related to reproduction.

\section{Breast cancer}

Table 2 shows some results of case-control studies of the association between phyto-oestrogens, measured as biomarkers, and breast cancer risk. In three studies urinary phyto-oestrogens were measured quantitatively, and a low excretion of phyto-oestrogens was associated with an increased risk of breast cancer (Ingram et al. 1997; Zheng et al. 1999). Recently, a case-control study of serum Enl levels and breast cancer risk was performed in eastern Finland, using data from 194 breast cancer cases and 208 community-based controls. An association was found between low Enl concentration and increased risk of breast cancer (Pietinen et al. 2001) in both premenopausal and post-menopausal women. Thus, some evidence for a protective effect of both isoflavone- and lignan-rich diets has been found in the three classical case-control studies listed in Table 2. In the classical case-control studies the urinary or blood samples are taken after diagnosis, which may result in a change in Enl concentrations that is related to changes made in diet because of the disease. The study of Pietinen et al. (2001) was, in this respect, on the borderline. The cases had suspected breast tumours, but blood samples were taken before diagnosis. In the first nested case-control study, no association was observed between the urinary concentration of Enl and risk of breast cancer (den Tonkelaar et al. 2001). In our own nested case-control study (248 cases and 492 controls), however, a low plasma Enl concentration, below the $12 \cdot 5$ th percentile (mean plasma Enl $2.8 \mathrm{nmol} / \mathrm{l}$ ), was associated with a significantly increased risk of breast cancer. The adjusted relative risk and $95 \% \mathrm{CI}$ at the lowest percentile were 1.6 (95\% CI 1.0, $2 \cdot 6)$. In the same study an increased risk was also found with high plasma Enl values (Hultén et al. 2002), particularly in two sub-cohorts with only incident cases. In a sub-cohort

Table 2. Case-control studies (classical or nested) of the association between the concentration of phyto-oestrogens in blood or urine and breast cancer $(\mathrm{BC})$ risk

\begin{tabular}{|c|c|c|c|}
\hline Reference & Country & Measurement method and study design & Findings \\
\hline Ingram et al. (1997) & Australia & $\begin{array}{l}\text { Urinary isoflavonoids and lignans } \\
\text { (classical) }\end{array}$ & $\begin{array}{l}\text { High enterolactone and equol excretion associated } \\
\text { with decreased risk of } \mathrm{BC}\end{array}$ \\
\hline Zheng et al. (1999) & China, Shanghai & $\begin{array}{l}\text { Urinary excretion of isoflavonoids } \\
\text { (classical) }\end{array}$ & $\begin{array}{l}\text { Low excretion of isoflavonoids associated with } \\
\text { increased BC risk }\end{array}$ \\
\hline $\begin{array}{l}\text { den Tonkelaar et al. } \\
\text { (2001) }\end{array}$ & The Netherlands & $\begin{array}{l}\text { Urinary enterolactone : creatinine and } \\
\text { genistein : creatinine (nested) }\end{array}$ & $\begin{array}{l}\text { No association between phyto-oestrogen excretion } \\
\text { and BC risk in post-menopausal women }\end{array}$ \\
\hline Pietinen et al. (2001) & Finland & Serum enterolactone (classical) & $\begin{array}{l}\text { Serum enterolactone inversely associated with risk } \\
\text { of BC }\end{array}$ \\
\hline Hultén et al. (2002) & Sweden & Plasma enterolactone (nested) & $\begin{array}{l}\text { High and low concentrations of plasma } \\
\text { enterolactone associated with increased BC risk }\end{array}$ \\
\hline
\end{tabular}


from a mammary screening programme with a high proportion of screening-detected cases, a non-significant decreased risk was found for subjects in the highest percentile for plasma Enl concentration.

The following hypotheses are presented for the observed contradictory results of epidemiological studies of breast cancer:

1. only classical case-control studies have provided a clear indication of an inhibitory effect of lignan-rich food on tumour growth with delayed onset of clinical cancer, while only one of the two existing prospective studies partly supports this relationship. Is it possible that the effect can only be monitored at diagnosis or in cases with a short latency time?

2. could the results obtained in case-control studies reflect secondary effects of the tumour or host defence on the biomarkers themselves?

3. heterogeneity of the material investigated, methodology and different sources of Enl precursors in different countries. The latter may be the most important factors.

\section{Prostate cancer}

Changing from the soyabean-rich low-fat low-animalprotein diet to a Western diet increases the risk of prostate cancer in Japanese men. The exact nature of the inhibitory factors present in Asian diets is unknown. Since Japanese men have very high urinary excretion of isoflavonoids, it has been suggested that phyto-oestrogens may make a large contribution to the inhibition of the growth of latent cancers (Adlercreutz et al. 1991, 1993). There is less variation between populations in latent cancers than in clinical cancer, which suggests that differences in diet may be important for the transformation and growth of prostate cancer to its clinically-detectable form. A decreased risk of prostate cancer was found in Adventist men (Mills et al. 1989) who have a high consumption of beans, lentils (Lens culinaris), peas (Pisum sativum) and some dried fruits (all dietary sources of phyto-oestrogens), and in men of Japanese ancestry in Hawaii (Severson et al. 1989) who consume large quantities of rice and tofu, a soyabean product containing isoflavonoids. In Finland the lowest incidence of prostate cancer occurs in the northeast regions, where there is a high consumption of rye bread (Pukkala et al. 1987; Kleemola et al. 1994).

In experiments on rats and nude mice it has been shown repeatedly that a high intake of rye bran and soyabean protein delays the early growth of hormone-sensitive prostate cancer (Landström et al. 1998), with increased tumour cell apoptosis (Bylund et al. 2000). The active component(s) in rye bran may be lignans and isoflavonoids, but other substances and/or mechanisms may also be involved, such as effects on insulin and insulin-like growth factor-1. Increased content of fat in a rye diet abolishes the beneficial effects on tumour acquisition, tumour cell apoptosis and tumour growth (Bylund et al. 2000). Dietary fat also decreased the urinary excretion of Enl, suggesting that it interfered with the formation of Enl in the gut, possibly by a reduced rate of microbial fermentation in the intestine. The observation that the cancer-protecting effects of components of traditional diets can be reduced simply by adding fat may be of considerable importance for the understanding of the geographical and temporal variation in the incidence of clinical prostate cancer (World Cancer Research Fund and the American Institute for Cancer Research, 1997). The intake of saturated fat may also be related to the continued existence of the disease, as was noted in a recent report (Meyer et al. 1999).

The experimental studies also clearly show that the effect of diet on prostate tumour growth is transient and that no effect is seen on aggressively-growing tumours. These results are supported by the observations made by Thompson's group in Canada of the effects of purified lignan extracts on experimental breast and colo-rectal cancers (Thompson, 1995).

Conflicting results have been found in the case-control studies completed to date, and the evidence is insufficient to permit any conclusion of a possible protective effect of a high intake of phyto-oestrogens against prostate cancer (Hirayama, 1979; Oishi et al. 1988). Some recent studies have, however, supported the concept that consumption of phyto-oestrogen-rich food is associated with a decreased risk (Key et al. 1997; Strom et al. 1999) and may affect prostate cancer biology (Demark-Wahnefried et al. 2001). A recent large prospective study on circulating Enl and risk of prostate cancer did not support the hypothesis that high circulating Enl is protective against prostate cancer (Stattin et al. 2002). The possible effects of diet on prostate cancer growth are most probably very complex, and the results of experimental studies suggest that adjustment for fat and energy intake should be made when studying the effects of lignans. For this purpose, large data sources are needed, such as those collected within the European Prospective Investigation into Cancer and Nutrition study (Riboli \& Kaaks, 1997).

\section{Colo-rectal cancer}

It has long been accepted that dietary factors, such as dietary fibre-rich food, may be protective against cancer of the colon and rectum (World Cancer Research Fund and the American Institute for Cancer Research, 1997). Recently, the concept of a protective effect of fruits, vegetables and wholegrain cereals has been challenged, since no protective effect has been observed in some recent prospective studies using dietary questionnaires (Fuchs et al. 1999; Pietinen et al. 1999). A lack of association has also been observed between colo-rectal cancer risk and intake of plant sterols, with wholegrain bread as an important source (Normén et al. 2001), or plasma Enl used as a biomarker for intake of dietary fibre-rich food (Lundin et al. 2001a).

To further increase the uncertainty, a recent prospective study provided new support for a protective effect of fibrerich food against colo-rectal cancer. In a study by Terry et al. (2001a), in a cohort of over 60000 women, individuals with a very low intake of fruit and vegetables had an increased risk. 
The conflicting findings emphasise the potential usefulness of intervention studies, identification of critical phytochemicals with adverse or protective effects on cancer and identification of biomarkers of food intake. Intervention trials to date have been inconclusive or negative, and in one study using a purified fibre fraction, ispaghula fibre, the treatment was even associated with an increased recurrence of colo-rectal adenomas. In another large-scale intervention study it was also found that a low-fat high-fibre diet was ineffective in preventing recurrence of colo-rectal adenomas (Schatzkin et al. 2000).

Although much evidence has accumulated in support of a protective effect of fibre-rich food against risk of colo-rectal cancer, follow-up studies may be warranted, employing extensive prospective data on colo-rectal cancers and using biomarkers for the dietary fibre complex such as Enl, and perhaps in the future more specific biomarkers, e.g. alkyresorcinols (for rye; Ross et al. 2001; Linko et al. 2002) and avenantramides (for oats).

\section{Stomach cancer (including cardia)}

A large number of case-control studies strongly point in the direction of a protective effect of foods rich in fibre (World Cancer Research Fund and the American Institute for Cancer Research, 1997). The results are highly consistent with a protective effect associated with wholegrain cereals. Further support is provided by a recent study on cardia cancer performed on a population-based case-control study (Terry et al. 2001b), where the protective association was strong for cardia cancer and somewhat weaker for adenocarcinomas of the lower oesophagus. Importantly, no indication of a protective effect was observed for oesophageal squamous cell carcinoma, which strongly supports the conclusion that recall bias has not been an important factor leading to bias in this study. One exciting possible mechanism for a protective effect of wholegrain cereals is connected with their binding properties in relation to $\mathrm{N}$-nitroso compounds (Kurtz \& Zhang, 2001). Some preliminary data were presented during a whole grain and human health conference in Finland in June 2001 by Jacobs (2001) based on results of prospective studies, which again indicate a protective effect of whole grains in the upper digestive tract.

\section{General conclusion regarding cancer studies in human subjects}

Based on the aggregated results from studies in human subjects performed to date, to conclude that rye, whole grains or phyto-oestrogens are protective against cancer is not possible. Some studies, however, have shown promising results, especially in relation to the upper digestive tract. A delay in clinical cancer may be very important from a public health perspective. Dietary intervention studies in human subjects are therefore needed that use various forms of end points, such as apoptosis in tumours and changes in prostate-specific antigen concentration. Unfortunately, dietary intervention trials are both costly and very timeconsuming. Nevertheless, they are needed for definitive evidence of the effects of the diets.

\section{Cardiovascular disease, stroke and myocardial infarction}

Morris et al. (1977) demonstrated a striking association between a high intake of cereal fibre and reduced incidence of CHD in men followed for 16-20 years. Since then, a number of large-scale epidemiological studies have strongly supported this finding of a protective effect of foods rich in dietary fibre, especially wholegrain products, against myocardial infarctions (Willett, 1998; Truswell, 2002). In relation to wholegrain rye, a study involving approximately 22000 middle-aged Finnish men found an inverse association between the amount of dietary fibre in the diet and the incidence of CHD. This group of men were followed over 6 years, and it was observed that the intake of cereal fibre, derived largely from rye, was more strongly negatively associated with the risk of myocardial infarction than was vegetable or fruit fibre. The protective effect of fibre was strongest for fatal events. The relative risk for fatal myocardial infarction was 0.45 for men with the highest intake of fibre (median, $28.9 \mathrm{~g} / \mathrm{d}$ ) compared with men with lowest intake of fibre (median, $12.4 \mathrm{~g} / \mathrm{d}$; Pietinen et al. 1996). Other recent studies have yielded similar results, showing cereal fibre to be strongly associated with a protective effect against myocardial infarction (Wolk et al. 1999; Liu et al. 2002). A similar association has also been observed for post-menopausal women, in this case between wholegrain food and ischaemic stroke, independent of other known cardiovascular disease risk factors (Liu et al. 2000). There are probably several mechanisms involved in the protective process, including effects on lipids, insulin metabolism and fibrinolysis. The major protective effects seem, however, to be unrelated to changes in blood cholesterol concentration. Components in wholegrain cereals, such as alkylresorcinols, phenols and lignans, can act as antioxidants (Jacobs et al. 1998; Vanharanta et al. 2002) and their antioxidant and anti-inflammatory properties may be related to disease-preventing mechanisms.

\section{Antioxidant or anti-inflammatory factors related to the whole-grain complex}

There are a large number of potential candidates in the whole-grain complex that have antioxidant and antiinflammatory properties. The alkylresorcinols have this potential and they are present at very high concentration in wholegrain rye and wheat. Theoretically, the presence in the vessel wall of a factor with anti-inflammatory activity may prevent 'plaque rupture' and subsequent thrombosis formation. A study on the absorption of alkylresorcinols in human subjects has recently been performed. Ten subjects who had undergone ileostomy were fed diets containing either whole-rye bread rich in alkylresorcinols or sifted wheat bread with no alkylresorcinols. Diets and ileostomy samples were analysed for alkylresorcinols, and the apparent digestibility was calculated. The average absorption of alkylresorcinols in human subjects was between 50 and $70 \%$ for all major homologues (Ross et al. 2001).

Recently it was shown that alkylresorcinols circulate in blood in the unconjugated form (Linko et al. 2002). The 
alkylresorcinol concentration in blood may therefore be considered a good marker for intake of whole cereal grain and, most probably, better than Enl concentration in blood as a marker for intake of whole-rye grain and wheat. Their biological effects and distribution in the body should certainly be studied further.

In the field of cardiovascular disease, in particular myocardial infarction, there is general agreement between the results of prospective studies that use biomarkers in blood with antioxidant properties, such as Enl (Vanharanta et al. 1999) and ascorbic acid (Khaw et al. 2001), and those of prospective studies that use dietary questionnaires. In a recent Finnish study a high serum concentration of Enl was clearly associated with a decreased risk of myocardial infarction (Vanharanta et al. 1999). Thus, in this study serum Enl was found to be a useful biomarker for the intake of lignan-rich foods. As with ascorbic acid and other antioxidants in blood, a negative correlation might be expected to exist between Enl and markers of inflammation in blood, a hypothesis that has not yet been tested. It is, however, unlikely that plasma Enl is confounded by the effect of a low-grade inflammation associated with advanced atherosclerosis. In fact, in a very recent study by Vanharanta et al. (2002), serum Enl was associated with decreased in vivo lipid peroxidation. This association remained even after adjustment for plasma antioxidant vitamins ( $\alpha$-tocopherol, $\beta$-carotene, ascorbic acid) and dietary folic acid. It was suggested, therefore, that Enl or some of its precursors might contribute to the antioxidant defence system in blood. Other biomarkers or phytochemicals may of course also be the active antioxidants.

\section{Conclusion}

There is strong evidence for a protective effect of a high intake of wholegrain products on myocardial infarction, and probably also on diabetes and stroke. It is concluded that the effects of a whole-grain diet, e.g. rye bran, on different risk factors may be associated with the reduced overall risk for myocardial infarction and stroke.

\section{Diabetes}

Diabetes is a well-established risk factor for cardiovascular disease. In a number of studies in human subjects and animals intake of rye bran has been associated with improved metabolic status or preventive effects on diabetes. The effect of bread with a high rye-bran content was compared in patients with insulin-dependent diabetes with the effects of either low-bran bread or the patients' usual bread (Nygren et al. 1984). When the bread with high ryebran content was included in the diet it was observed that the glucose profile during the day improved or the insulin doses could be reduced.

Protective effects of rye bran on the diabetes syndrome have also been found in rats and mice (Nygren et al. 1981; Lundin et al. 2001b). Diabetic rats fed a high-fibre bread lost less body weight, and exhibited lower blood glucose levels and lower urinary glucose excretion than the animals fed a low-fibre bread. Another study found that rye bran slightly lowered blood glucose levels and led to slower weight gain in normal rats and mice and prolonged survival of diabetic mice (Berglund et al. 1982).

It has long been recognised that a high intake of wheat bran or a mixture of wheat and rye bran improves glucose tolerance in human subjects without diabetes (Brodribb \& Humphreys, 1976; Sandman et al. 1983) and in individuals with glucose intolerance (Bosello et al. 1980). It has recently been observed in an experimental study that increased intake of whole grains is associated with increased insulin sensitivity (Pereira et al. 2002). A clear association between a high intake of dietary fibre from cereal grain and a reduced risk of diabetes has also been observed in two large-scale prospective studies in women. In one of the studies a low glycaemic index was concomitantly associated with a decreased risk (Salmeron et al. 1997) in younger women. However, the second, more recent study (Meyer et al. 2000) on older women did not support this finding. The outcomes of the epidemiological and experimental studies performed to date suggest that substituting refinedgrain products with wholegrain products may decrease the risk of both diabetes and cardiovascular disease. It is also reasonable to assume that the protective effect is associated with some factor in the dietary fibre complex. At present, no studies on diabetes have so far been published that use biomarkers such as Enl for food intake.

\section{Conclusion}

Experimental evidence suggests that increased fibre intake, with a high intake of whole grains, is related to increased insulin sensitivity. Furthermore, intake of wholegrain products was associated with a decreased risk of diabetes in women in two prospective studies. Thus, the outcome of epidemiological and experimental studies suggests that substitution of refined-grain products with wholegrain products may decrease the risk of, or alternatively delay, the onset of diabetes. It is also reasonable to assume that the protective effect is associated with some factor(s) in the dietary fibre complex.

\section{References}

Adlercreutz H, Honjo H, Higashi A, Fotsis T, Hämäläinen E, Hasegawa T \& Okada H (1991) Urinary excretion of lignans and isoflavonoid phytoestrogens in Japanese men and women consuming a traditional Japanese diet. American Journal of Clinical Nutrition 54, 1093-1100.

Adlercreutz H, Markkanen H \& Watanabe S (1993) Plasma concentrations of phyto-oestrogens in Japanese men. Lancet 342, $1209-1210$.

Adlercreutz H \& Mazur W (1997) Phyto-oestrogens and Western diseases. Annals of Medicine 29, 95-120.

Berglund O, Hallmans G, Nygren C \& Taljedal IB (1982) Effects of diets rich and poor in fibres on the development of hereditary diabetes in mice. Acta Endocrinologia (Copenhagen) 100, 556-564.

Bosello O, Ostuzzi R, Armellini F, Micciolo R \& Scuro LA (1980) Glucose tolerance and blood lipids in bran-fed patients with impaired glucose tolerance. Diabetes Care 3, 46-49.

Brodribb AJ \& Humphreys DM (1976) Diverticular disease: three studies. Part III - Metabolic effect of bran in patients with diverticular disease. British Medical Journal 1, 428-430. 
Bylund A, Zhang JX, Bergh A, Damber JE, Widmark A, Johansson A, Adlercreutz H, Aman P, Shepherd MJ \& Hallmans G (2000) Rye bran and soy protein delay growth and increase apoptosis of human $\mathrm{LNCaP}$ prostate adenocarcinoma in nude mice. Prostate 42, 304-314.

Demark-Wahnefried W, Price DT, Polascik TJ, Robertson CN, Anderson EE, Paulson DF, Walther PJ, Gannon M \& Vollmer RT (2001) Pilot study of dietary fat restriction and flaxseed supplementation in men with prostate cancer before surgery: exploring the effects on hormonal levels, prostate-specific antigen, and histopathologic features. Urology 58, 47-52.

den Tonkelaar I, Keinan-Boker L, Veer PV, Arts CJ, Adlercreutz H, Thijssen JH \& Peeters PHM (2001) Urinary phytoestrogens and postmenopausal breast cancer risk. Cancer Epidemiology, Biomarkers and Prevention 10, 223-228.

Fuchs CS, Giovannucci EL, Colditz GA, Hunter DJ, Stampfer MJ, Rosner B, Speizer FE \& Willett WC (1999) Dietary fiber and the risk of colorectal cancer and adenoma in women. New England Journal of Medicine 340, 69-176.

Hallmans G, Zhang JX, Lundin E, Bergh A, Sylvan A, Bylund A, Widmark A, Stattin P, Damber JE, Åman P, Johansson A \& Adlercreutz H (1999) Metabolism of lignans and their relation to prostate cancer. In Phytoestrogens: Exposure, Bioavailability, Health Benefits and Safety Concerns. Proceedings of International Symposium, COST 916, Bioactive Plant Cell Wall Components in Nutrition and Health, pp. 65-72 [S BauschGoldbohm, A Kardinaal and F Serra, editors]. Doorweth, The Netherlands: Commission of European Communities.

Heinonen S, Nurmi T, Liukkonen K, Poutanen K, Wähälä $K$, Deyama T, Nishibe S \& Adlercreutz H (2001) In vitro metabolism of plant lignans: new precursors of mammalian lignans enterolactone and enterodiol. Journal of Agricultural and Food Chemistry 49, 3178-3186.

Hirayama T (1979) Epidemiology of prostate cancer with special reference to the role of diet. National Cancer Institute Monographs 53, 149-155.

Hultén K, Winkvist A, Lenner P, Johansson R, Adlercreutz H \& Hallmans G (2002) An incident case referent study on plasma enterolactone and breast cancer risk. European Journal of Nutrition 41, 168-176.

Ingram D, Sanders K, Kolybaba M \& Lopez D (1997) Casecontrol study of phyto-oestrogens and breast cancer. Lancet 350, 990-994.

Jacobs DR (2001) The health relevance of whole grain. In Whole Grain and Human Health, Proceedings of International Symposium VTT 213, Espoo, Finland, pp. 17-18 [K Liukkonen, A Kuokka and K Poutanen, editors]. Espoo, Finland: VTT.

Jacobs DR Jr, Meyer KA, Kushi LH \& Folsom AR (1998) Wholegrain intake may reduce the risk of ischemic heart disease death in postmenopausal women: The Iowa Women's Health Study. American Journal of Clinical Nutrition 68, 248-257.

Juntunen K, Witold M, Liukkonen K, Mariko U, Poutanen K, Adlercreutz H \& Mykkänen H (2000) Consumption of wholemeal rye bread increases serum concentrations and urinary excretion of enterolactone compared with wheat bread in healthy Finnish men and women. British Journal of Nutrition 84, 839-846.

Key TJA, Silcocks PB, Davey GK, Appleby PN \& Bishop DT (1997) A case control study of diet and prostate cancer. British Journal of Cancer 76, 678-687.

Khaw KT, Bingham S, Welch A, Luben R, Wareham N, Oakes S \& Day N (2001) Relation between plasma ascorbic acid and mortality in men and women in EPIC - Norfolk prospective study: a prospective population study. European Prospective Investigation into Cancer and Nutrition. Lancet 357, 657-663.

Kilkkinen A, Stumpf K, Pietinen P, Valsta LM, Tapanainen H \& Adlercreutz H (2001) Determinants of serum enterolactone concentration. American Journal of Clinical Nutrition $\mathbf{7 3}$, 1094-1100.

Kleemola P, Virtanen M \& Pietinen P (1994) The 1992 Dietary Survey of Finnish Adults. Helsinki, Finland: Helsinki National Public Health Institute, Department of Nutrition.

Kurtz RC \& Zhang ZF (2001) Gastric cardia cancer and dietary fiber. Gastroenterology 120, 568-570.

Landström M, Zhang JX, Hallmans G, Åman P, Berg A, Damber JE, Mazur W, Wähälä K \& Adlercreutz H (1998) Inhibitory effects of soy and rye diets on the development of Dunning R3327 prostate adenocarcinoma in rats. Prostate 36 151-161.

Linko AM, Parikka K, Wähälä K \& Adlercreutz H (2002) Gas chromatographic-mass spectrometric method for the determination of alkylresorcinols in human plasma. Analytical Biochemistry 308, 307-313.

Liu S, Buring JE, Sesso HD, Rimm EB, Willett WC \& Manson JE (2002) A prospective study of dietary fiber intake and risk of cardiovascular disease among women. Journal of the American College of Cardiology 39, 49-56.

Liu S, Manson JE, Stampfer MJ, Rexrode KM, Hu FB, Rimm EB \& Willett WC (2000) Whole grain consumption and risk of ischemic stroke in women: A prospective study. Journal of the American Medical Association 284, 1534-1540.

Lundin E, Adlercreutz H, Bianchini F, Stenling R, Riboli E, Kaaks R, Hallmans G \& Palmqvist R (2001a) No association between plasma enterolactone and colorectal cancer risk in a prospective study. In The Dietary Fiber Complex, Intestinal Function and Metabolic Effects. Experimental and Epidemiology Studies. Umeå University Medical Dissertation. Umeå, Sweden: Umeå University.

Lundin E, Nygren C, Berglund O, Zhang JX, Höstedt P, Hallmans G \& Stenling R (2001b) Effects of a rye bran diet and a fiber free diet on the morphology of the small intestine of diabetic and control mice. A scanning and transmission electron microscopy study. In The Dietary Fiber Complex, Intestinal Function and Metabolic Effects. Experimental and Epidemiology Studies. Umeå University Medical Dissertation. Umeå, Sweden: Umeå University.

Mazur W (1998) Phytoestrogen content in foods. Bailliere's Clinical Endocrinology and Metabolism 12, 729-742.

Mazur W \& Adlercreutz H (1998) Naturally occurring oestrogens in food. Pure and Applied Chemistry 70, 1759-1776.

Mazur W, Fotsis T, Wähälä K, Ojala S, Salakka A \& Adlercreutz H (1996) Isotope dilution gas chromatographic-mass spectrometric method for the determination of isoflavonoids, coumestrol, and lignans in food samples. Analytical Biochemistry 233, 169-180.

Meyer F, Bairati I, Shadimani R, Fradet Y \& Moore L (1999) Dietary fat and prostate cancer survival. Cancer Causes and Control 10, 245-251.

Meyer KA, Kushi LH, Jacobs DR Jr, Slavin J, Sellers TA \& Folsom AR (2000) Carbohydrates, dietary fiber, and incident type 2 diabetes in older women. American Journal of Clinical Nutrition 71, 921-930.

Mills P, Beeson B, Phillips R \& Fraser G (1989) Cohort study of diet, lifestyle and prostate cancer in Adventist men. Cancer 64, 598-604.

Morris JN, Marr JW \& Clayton DG (1977) Diet and heart: A postscript. British Medical Journal 2, 1307-1314.

Nilsson M, Åman P, Härkönen H, Hallmans G, Bach Knudsen KE, Mazur W \& Adlercreutz H (1997a) Content of nutrients and lignans in roller milled fractions of rye. Journal of the Science of Food and Agriculture 73, 143-148.

Nilsson M, Åman P, Härkönen H, Hallmans G, Bach Knudsen KE, Mazur W \& Adlercreutz H (1997b) Nutrient and lignan content, dough properties and baking performance of rye samples used in Scandinavia. Acta Agriculturae Scandinavica 47B, 26-34. 
Normén AL, Brants HA, Voorrips LE, Andersson HA, van den Brandt PA \& Goldbohm RA (2001) Plant sterol intakes and colorectal cancer risk in the Netherlands Cohort Study on Diet and Cancer. American Journal of Clinical Nutrition 74, 141-148.

Nygren C, Hallmans G \& Lithner F (1981) Long term effects of dietary fibre in bread on weight, blood glucose, glucosuria and faecal fat excretion in alloxan diabetic rats. Diabete et Metabolisme 7, 115-120.

Nygren C, Hallmans G \& Lithner F (1984) Effect of high-bran bread on blood glucose control in insulin-dependent diabetic patients. Diabete et Metabolisme 10, 39-43.

Oishi K, Okada K, Yoshida O, Yamabe H \& Ohno Y (1988) A casecontrol study of prostatic cancer with reference to dietary habit. Prostate 12, 179-190.

Pereira MA, Jacobs DR Jr, Pins JJ, Raatz KS, Gross MD, Slavin JL \& Seaquist ER (2002) Effect of whole grains on insulin sensitivity in overweight hyperinsulinemic adults. American Journal of Clinical Nutrition 75, 848-855.

Pettersson D, Åman P, Bach Knudsen KE, Lundin E, Zhang JX, Hallmans G, Härkönen H \& Adlercreutz H (1996) Intake of rye bread by ileostomists increases ileal excretion of fiber polysaccharide components and organic acids but does not increase plasma or urine lignans and isoflavonoids. Journal of Nutrition 126, 1594-1600.

Pietinen P, Malila N, Virtanen M, Hartman TJ, Tangrea JA, Albanes D \& Virtamo J (1999) Diet and risk of colorectal cancer in a cohort of Finnish men. Cancer Causes and Control 10, 387-396.

Pietinen P, Rimm EB, Korhonen P, Hartman AM, Willett WC, Albanes D \& Virtamo J (1996) Intake of dietary fiber and risk of coronary heart disease in a cohort of Finnish men. Circulation 94, 2720-2727.

Pietinen P, Stumpf K, Mannisto S, Kataja V, Uusitupa M \& Adlercreutz H (2001) Serum enterolactone and risk of breast cancer: a case-control study in eastern Finland. Cancer Epidemiology, Biomarkers and Prevention 10, 339-344.

Pukkala E, Gustavsson N \& Teppom L (1987) Atlas of Cancer Incidence in Finland, p. 37. Helsinki, Finland: Offset/PKK Oy.

Riboli E \& Kaaks R (1997) The EPIC Project: rationale and study design. European Prospective Investigation into Cancer and Nutrition. International Journal of Epidemiology 26, Suppl. 1, S6-S14.

Ross AB, Kamal-Eldin A, Åman P, Lundin E, Zhang JX \& Hallmans G (2001) Alkylresorcinols are absorbed by humans. In Whole Grain and Human Health. Proceedings of International Symposium, VTT 213, Espoo, Finland, p. 93 [K Liukkonen, A Kuokka and K Poutanen, editors]. Espoo, Finland: VTT.

Rowland IR, Wiseman H, Sanders TA, Adlercreutz H \& Bowey EA (2000) Interindividual variation in metabolism of soy isoflavones and lignans: influence of habitual diet on equol production by the gut microflora. Nutrition and Cancer 36, 27-32.

Salmeron J, Manson JAE, Stampfer MJ, Golditz GA, Wing AL \& Willett WC (1997) Dietary fiber, glycemic load, and risk of non-insulin-dependent diabetes mellitus in women. Journal of the American Medical Association 277, 472-477.

Sandman PO, Adolfsson R, Hallmans G, Nygren C, Nystrom L \& Winblad B (1983) Treatment of constipation with high-bran bread in long-term care of severely demented elderly patients. Journal of the American Geriatrics Society 31, 289-293.
Schatzkin A, Lanza E, Corle D, Lance P, Iber F, Caan B, Shike M, Weissfeld J, Burt R, Cooper MR, Kikendall JW \& Cahill J (2000) Lack of effect of a low-fat, high-fiber diet on the recurrence of colorectal adenomas. Polyp Prevention Trial Study Group. New England Journal of Medicine 342, 1149-1155.

Severson R, Nomura A, Grove J \& Stemmermann G (1989) A prospective study of demographies, diets and prostatic cancer among man of Japanese ancestry in Hawaii. Cancer Research 49, $1857-1860$.

Stattin P, Adlercreutz H, Tenkanen L, Jellum E, Lumme S, Hallmans G, Harvei S, Teppo L, Stumpf K, Luostarinen T, Lehtinen M, Dillner J \& Hakama M (2002) Circulating enterolactone and prostate cancer risk: a Nordic nested case-control study. International Journal of Cancer 99, 124-129.

Strom SS, Yamamura Y, Duphrone CM, Spitz MR, Babaian RJ, Pillow PC \& Hursting SD (1999) Phytoestrogen intake and prostate cancer: A case-control study using a new data base. Nutrition and Cancer 33, 20-25.

Stumpf K, Pietinen P, Puska P \& Adlercreutz H (2000) Changes in serum enterolactone, genistein, and daidzein in a dietary intervention study in Finland. Cancer Epidemiology Biomarkers and Prevention 9, 1369-1372.

Terry P, Giovannucci E, Michels KB, Bergkvist L, Hansen H, Holmberg L \& Wolk A (2001a) Fruit, vegetables, dietary fiber, and risk of colorectal cancer. Journal of the National Cancer Institute 93, 525-533.

Terry P, Lagergren J, Ye W, Wolk A \& Nyren O (2001b) Inverse association between intake of cereal fiber and risk of gastric cardia cancer. Gastroenterology 120, 387-391.

Thompson LU (1995) Flaxseed, lignans, and cancer. In Flaxseed in Human Nutrition, pp. 219-236 [SC Cunnane and LU Thompson, editors]. Champaign, IL: AOCS Press.

Truswell AS (2002) Cereal grains and coronary heart disease. European Journal of Clinical Nutrition 56, 1-14.

Vanharanta M, Voutilainen S, Lakka TA, van der Lee M, Adlercreutz H \& Salonen JT (1999) Risk of acute coronary events according to serum concentrations of enterolactone: a prospective population-based case-control study. Lancet 354, 2112-2115

Vanharanta M, Voutilainen S, Nurmi T, Kaikkonen J, Roberts LJ, Morrow JD, Adlercreutz H \& Salonen JT (2002) Association between low serum enterolactone and increased plasma $\mathrm{F}_{2}$ isoprostanens, a measure of lipid peroxidation. Atherosclerosis 160, 465-469.

Willett WC (1998) The Dietary Pyramid: does the foundation need repair? American Journal of Clinical Nutrition 68, 218-219.

Wolk A, Manson JE, Stampfer MJ, Colditz GA, Hu FB, Speizer FE, Hennekens CH \& Willett WC ((1999) Long-term intake of dietary fiber and decreased risk of coronary heart disease among women. Journal of the American Medical Association 281, 1998-2004.

World Cancer Research Fund and the American Institute for Cancer Research (1997) Food, Nutrition and The Prevention of Cancer: A Global Perspective. Washington, DC: American Institute for Cancer Research.

Zheng W, Dai Q, Custer LJ, Shu XO, Wen WQ, Jin F \& Franke AA (1999) Urinary excretion of isoflavonoids and the risk of breast cancer. Cancer Epidemiology, Biomarkers and Prevention 8, $35-40$. 